Family correlates of childhood binge eating:

A systematic review

Jaclyn A. Saltzman, M.P.H. ${ }^{1,2}$

Janet M. Liechty, Ph.D., L.C.S.W. ${ }^{2,3}$

${ }^{1}$ Doctoral student, Department of Human Development and Family Studies, University of Illinois, Doris Kelly Christopher Hall, 904 W. Nevada Street, MC-081, Urbana, Illinois, USA. Email: saltzmn2@illinois.edu

${ }^{2}$ Illinois Transdiscplinary Obesity Prevention Program (I-TOPP), University of Illinois ${ }^{3}$ Associate Professor, School of Social Work and College of Medicine, University of Illinois, 1010 W. Nevada Street, Urbana, Illinois, USA. Email: jliechty@illinois.edu

Keywords: Binge Eating Disorder; Binge eating in children; Loss of control eating; Systematic review; Review of correlates; Family; Parent

Abstract word count: 249

Manuscript word count (excluding figures, appendices tables and references): 3998

Corresponding Author:

Jaclyn A. Saltzman, M.P.H.

Email: saltzmn2@illinois.edu

Telephone: (847)754-7652 


\begin{abstract}
Objective: Binge Eating Disorder is the most prevalent eating disorder in the US, and binge eating has been identified in children as young as five. As part of a larger registered systematic review, we identified family correlates of binge eating in children (C-BE) aged 12 and under. Method: Using established guidelines, we searched PubMed and PsycInfo for peer-reviewed studies published in English between 1980-April 2015 that examined family correlates and predictors of C-BE. This yielded 736 records for review; after exclusions fifteen studies were reviewed. Risk of bias was assessed. A risk factor typology was used to classify correlates. Results: Nine of the included studies were cross-sectional and six longitudinal. Family weight teasing and parent emotional unresponsiveness were correlates of C-BE. Parent weight, education/socio-economic situation, and parent race/ethnicity were not associated with C-BE in any study reviewed. There was insufficient or unclear evidence regarding associations between C-BE and parent disordered eating, weight or thinness concern, harsh discipline, maternal dieting, attachment security, and mealtimes and feeding practices. Limitations included too few studies on many of the correlates to summarize, inconsistency of findings, homogenous samples, and predominately cross-sectional designs. Discussion: Weight-related teasing in families and parental emotional unresponsiveness are correlates of $\mathrm{C}-\mathrm{BE}$ and important areas to address in parent education and eating disorder prevention programs with families. Further longitudinal studies on putative risk factors for binge eating in childhood are needed to address current limitations, enable synthesis across studies, and inform public health efforts to prevent binge eating problems in children.
\end{abstract}




\section{FAMILY CORRELATES OF CHILDHOOD BINGE EATING: A SYSTEMATIC REVIEW}

Binge Eating Disorder (BED; American Psychiatric Association, 2013) is the most prevalent eating disorder across all race/ethnic groups and among both male and female adolescents (Swanson, Crow, Le Grange, Swendsen \& Merikangas, 2011). Binge eating (BE) onset has been reported in children as young as five, and the lifetime prevalence of BED among US adolescents is more than five times greater than that of Anorexia and twice that of Bulimia (Swanson et al., 2011). BED is associated with psychological and physical health issues in adolescents and adults—-such as depression (Araujo, Santos, \& Nardi, 2010) and obesity (de Zwaan, 2001)_-rendering it a significant public health concern. To date there have been no US surveillance studies of the prevalence or incidence of BE among children aged 12 and under, although research on loss of control (LOC) eating among children aged 6-14 suggests that prevalence rates range from 2-10\% (Tanofsky-Kraff, Marcus, Yanovski, \& Yanovski, 2008). However, there has been no systematic review of risk factors for child BE (C-BE) for more than a decade (Marcus \& Kalarchian, 2003), and we found no prior systematic review of family factors of BE.

Most research on $\mathrm{BE}$ in children $(\mathrm{C}-\mathrm{BE})$ has focused on cognitions and behaviors—-such as negative affect (Pearson, Zapolski, \& Smith, 2015), self-regulation (Czaja, Rief, \& Hilbert, 2009), and dieting (Tanofsky-Kraff, Faden, Yanovski, Wilfley, \& Yanovski, 2005)—with less attention devoted to the context in which these characteristics develop. Socio-Ecological and Ecological Systems Theories posit that bidirectional interactions between various, nested settings influence individual development, and that the family is the most proximal and influential setting affecting behaviors, attitudes, and resource access for children (Bronfenbrenner, 1979; Davison 
\& Birch, 2001; Grusec \& Davidov, 2015). Family demographics and resources (e.g. socioeconomic situation [SES]), as well as individual parent (e.g. parent dieting) and relational characteristics (e.g. attachment security) have all been examined as putative family correlates of C-BE, but to date there has been no synthesis of this literature.

To address this gap, we conducted a systematic review of the literature on family correlates of BE in children aged 12 and under. First, we summarize associations by study and assess the risk of bias across studies. We then classify correlates according to an established risk factor typology to highlight current applicability of findings to C-BE prevention (Kraemer et al., 1997). Finally, we discuss findings, future directions, and implications of research on family correlates of childhood binge eating.

\section{METHODS}

\subsection{Protocol registration}

Studies in this review are the product of a focused search on family factors and correlates of C-BE drawn from a larger systematic review of the literature about correlates of C-BE which was conducted under a protocol registered on the International Prospective Register of Systematic Reviews (PROSPERO; see Saltzman, Liechty, \& Badskey, 2013). The initial pool of eligible studies was the same as for the larger review. For this study, a more focused set of exclusion criteria was applied to the full-text review process in order to narrow the pool to those studies that examined family correlates. We used guidelines from the Preferred Reporting Items for Systematic Reviews and Meta-Analysis (PRISMA; Moher, Liberati, Tetzlaff, \& Altman, 2009) as well as the PROSPERO registration system to ensure review process transparency, and to improve quality and confidence in findings (Figure 1). 


\subsection{Inclusion and exclusion criteria}

Inclusion and exclusion criteria for this review were the same as for the larger study discussed in section 2.1, with the addition of the ninth inclusion and sixth exclusion criteria that narrowed the review to family correlates (Table 1). Because childhood is defined as ages birth to 12-years-old (US Department of Health and Human Services, 2015), we used this range for the review.

\subsection{Search and selection}

PubMed and PsycInfo were searched to identify peer-reviewed studies using the following terms: "binge eating," "binge eating disorder," "LOC," or "loss of control;" and truncated variations of the terms "associate," "predict," "correlate," "risk," "characteristic," and "causal." In addition, we applied filters for age (birth-12 years), English language, and publication date (1980-April 2015). Loss of control (LOC) eating is a prominent symptom of BED among adults (White \& Grilo, 2011), and research criteria for LOC-Eating Disorder successfully differentiates children by severity of disordered eating, and children with disordered eating from healthy peers (Goldschmidt et al., 2008; Matherne et al., 2015; Tanofsky-Kraff, Marcus, Yanovski, \& Yanovski, 2008). Because both LOC and C-BE were included in this review, we use the term CBE to discuss overall findings, but specify when studies measured LOC eating.

We identified 736 records for review after removing duplicates. Abstracts and titles were screened for inclusion/exclusion criteria by the first author, and 625 studies were excluded. The full-text of the remaining studies $(n=111)$ were screened for eligibility (see Figure 1$)$. Fifteen studies were included in this review.

\subsection{Extraction and coding}

The data extraction protocol is in accordance with PRISMA guidelines (Moher et al., 2009). After abstracts were screened, full-text records were appraised, and the following 
information was recorded: record title, author name(s), date and country of study, sample size and characteristics, study design, measures used, and results relevant to this review (Table 2). For longitudinal studies, only the available data on children 12 and under were included.

\subsection{Risk of bias}

Risk of bias was assessed using design-specific (e.g. case-control, cohort) quality assessment tools from the National Heart, Lung, and Blood Institute (NHLBI, 2014). As others have reported, there are few validated tools for assessment of risk of bias in non-randomized, observational studies (Sanderson, Tatt, \& Higgins, 2007; Stang, 2010); and so several risk of bias tools were piloted on non-included studies to assess feasibility for this review. The NHLBI tools were chosen due to their methodologically rigorous development by expert panels and availability of detailed user-guidance documents. Users are instructed not to use the tools to obtain scores for comparing studies, but rather to focus on key attributes relevant to the internal and external validity of studies (NHLBI, 2014). Risk of bias assessments focused on the measures and other validity issues most relevant to findings used in this review, and do not necessarily reflect the overall quality of individual studies.

Both authors evaluated risk of bias using the NHLBI tools, and gave each study a rating of "Good," "Fair," or "Poor" according to guidelines; discrepancies were discussed and resolved by consensus. Studies given a rating of "Good" have minimal risk of bias; those rated "Fair" have moderate risk of bias; and studies rated "Poor" have high risk of bias. No studies were excluded from synthesis.

\subsection{Evaluating findings and classifying correlates}

Putative correlates identified in Table 2 were included in summary synthesis (Table 3 ) if two or more studies assessed the same — or a conceptually similar — category of correlates. We 
classified constructs by study design, according to guidelines for the risk factor typology (Kraemer et al., 1997; Jacobi et al., 2004). Correlates were identified by cross-sectional studies, and risk factors by longitudinal studies. If more than half of the cross-sectional studies assessing a construct found consistent results, the construct was classified as a "non-correlate" (no association) or a "correlate" (positive or negative associations). If more than half of the longitudinal studies assessing a construct found that it predicted $\mathrm{C}-\mathrm{BE}$, the construct was classified as a risk factor. If half or fewer of the longitudinal studies or cross-sectional studies assessing a construct had consistent results, the construct was classified as "unclear." If only two studies assessed a construct, it was not classified due to insufficient evidence, and was labeled "N/A."

\section{RESULTS}

Of the 736 records screened for this review, 15 articles were included. Of the included studies $(n=15)$, nine were cross-sectional and six were longitudinal. Table 2 summarizes characteristics of included studies.

\subsection{Sample characteristics}

Included studies were conducted in the US $(n=7)$, Germany $(n=4)$, and Belgium $(n=4)$; few reported whether their samples were collected from urban, suburban, or rural settings. Three studies sampled only girls (Chen, McCloskey, \& Kathryn, 2009; Olvera, Dempsey, Gonzalez, \& Abrahamson, 2013; Spanos, Klump, Alexandra, McGue, \& Iacono, 2010), or only obese/overweight children (Decaluwé, Braet, Moens, \& Van Vlierberghe, 2006; Olvera et al., 2013; Pauli-Pott, Becker, Albayrak, Hebebrand, \& Pott, 2013). Six studies' samples were majority White (>50\%; $m=76.7 \%$; Chen et al., 2009; Field et al., 2008; Haines, Gillman, RifasShiman, Field, \& Austin, 2010; Shomaker et al., 2010; Spanos et al., 2010; Stice, Agras, \& 
Hammer, 1999), and eight studies did not report racial/ethnic demographics (Czaja, Hartmann, Rief, \& Hilbert, 2011; Decaluwé et al., 2006; Goossens, Braet, Bosmans, \& Decaluwé, 2011;

Goossens, Braet, Durme, Decaluwé, \& Bosmans, 2012; Hartmann, Czaja, Rief, \& Hilbert, 2012; Lamerz et al., 2005; Matton, Goossens, Braet, \& Van Durme, 2013; Pauli-Pott et al., 2013). Consistent with reporting norms, the studies that did not report racial/ethnic demographics were from Europe, and all but two reported or matched on SES (Decaluwé et al., 2006; Goossens et al., 2012). Of the seven US studies, all reported on race/ethnicity, and five reported or matched on SES (Chen et al., 2009; Field et al., 2008; Olvera et al., 2013; Shomaker et al., 2010; Stice et al., 1999).

Sample sizes ranged from small clinical samples $(n=74)$, to large surveillance studies $(n=$ 13488). The mean sample size was $n=2678$ for cohort studies, and $n=261$ for case-control studies. Mean sample age of included studies ranged from 3-weeks to 12.7-years old.

\subsection{Risk of bias summary}

\subsubsection{Case-control studies $(n=4)$}

Four cross-sectional studies used a case-control design. According to the NHLBI quality assessment tool, two were assessed as good and two as fair, representing minimal and moderate risk of bias, respectively. Strengths included use of concurrent controls, defined and valid measures, clear differentiation between cases and controls, and consistent application of definitions, inclusion/exclusion criteria, and processes to identify cases and controls. Weaknesses included lack of reporting on recruitment location (e.g. rural, urban, suburban), sample size justification, and whether controls and cases were recruited from the same population. No studies blinded assessors to treatment assignment. Finally, three studies did not adequately account for confounders or matching, according to NHBLI criteria. 


\subsubsection{Cohort studies $(n=11)$}

Five cross-sectional studies and six longitudinal studies used a cohort design. Of the crosssectional studies, four were assessed as fair and one poor, representing moderate and high risk of bias, respectively. Of the six longitudinal studies, three were assessed as good and three as fair. Strengths of the cohort studies included using clearly stated objectives, adequate timing for exposure and outcome measurements, and consistent application of inclusion and exclusion criteria for study participation. Some weaknesses included lack of reporting on recruitment location, sample size justification, lack of assessor blinding, and use of single- or two-item measures of BE.

\subsection{Family correlates of childhood binge eating}

Results across correlates are summarized in Table 3.

\subsubsection{Parent weight}

Three studies found no effect of parents' weight on C-BE. One used a 5-year birth cohort (Stice et al., 1999), and two were cross-sectional studies of children 8-13 years old (Decaluwé et al., 2006; Hartmann et al., 2012). Measurement differences between studies are discussed in section 4.2.1.

\subsubsection{Parent disordered eating}

Four studies examined the effect of parent disordered eating on C-BE, however there was little consistency in the type of disordered eating studied. One longitudinal study found that maternal bulimic symptoms had no effect on 5-year-old children's overeating (Stice et al., 1999). Two cross-sectional studies found no effect of maternal history of disordered eating on child LOC (Field et al., 2008; Hartmann et al., 2012). However, one cross-sectional, population-based study found that maternal BE was associated with increased risk of C-BE (Lamerz et al., 2005). 


\subsubsection{Parental weight teasing}

Four studies - three cross-sectional, one longitudinal — examined the effect of parents' weight-related teasing on C-BE. All cross-sectional studies found an association between weight teasing and C-BE/LOC (Field et al., 2008; Hartmann et al., 2012; Olvera et al., 2013), however the longitudinal study found no association (Haines et al., 2010).

\subsubsection{Family weight concern}

Four studies examined whether parent concern for thinness, shape or weight was associated with C-BE, with mixed findings. Two longitudinal cohort studies found a positive association between weight concern (among fathers only) or thinness concern and BE/LOC (Field et al., 2008; Stice et al., 1999). A cross-sectional case-control and a longitudinal study found no association (Haines et al., 2010; Hartmann et al., 2012).

\subsubsection{Parenting behavior}

Three cross-sectional studies examined associations between various parenting behaviors and C-BE (Czaja et al., 2011; Decaluwé et al., 2006; Hartmann et al., 2012), with mixed results depending on specific behavior. Studies found that more maternal ignoring (Decaluwé et al., 2006), and less interpersonal involvement (Czaja et al., 2011; Hartmann et al., 2012) were related to LOC eating. LOC eating was associated with lower overall family functioning (Czaja et al., 2011), but not with harsh discipline (Czaja et al., 2011; Decaluwé et al., 2006; Hartmann et al., 2012).

\subsubsection{Maternal restraint/dieting}

One cross-sectional and two longitudinal studies examined maternal dieting and C-BE, with mixed results. Maternal dietary restraint at birth was related to report of child overeating at 5years-old (Stice et al., 1999). However, using a larger sample of mothers from the Growing Up 
Today Study (GUTS) cohort — predominantly White and middle-class — another study found no association between mother-reported dieting at baseline, and child-report of BE at one-year follow-up (Haines et al., 2010). Lastly, a smaller cross-sectional study found that family members' dieting was not related to LOC (Hartmann et al., 2012).

3.3.7. Mealtimes and feeding practices

Associations between LOC eating and mealtimes was examined in one longitudinal and one cross-sectional study (Czaja et al., 2011; Haines et al., 2010). In the longitudinal GUTS cohort, having family dinner most or every day predicted less C-BE a year later (Haines et al., 2010). Cross-sectionally, children with LOC eating did not differ from controls on mealtime duration, family members present, or meal location (Czaja et al., 2011).

One longitudinal cohort study found that parents' baseline feeding practices did not predict LOC eating among 12-year-olds (Matton et al., 2013). However, the study did find an association between maternal pressure-to-eat and overeating among girls 6-months later(Matton et al., 2013).

\subsubsection{Attachment}

Two Belgian studies examined attachment in relation to LOC eating among 8-11 year olds (Goossens et al., 2011, 2012). Cross-sectionally, there was a negative association between secure attachment to either parent and LOC eating; attachment also mediated children's low self-esteem and LOC eating (Goossens et al., 2011). Longitudinally, lower secure attachment towards fathers predicted persistence — but not onset — of subjective BE (Goossens et al., 2012).

3.3.9. Parent education, SES, family structure, and race/ethnicity

Two studies found no effect of SES on C-BE (Chen et al., 2009; Shomaker et al., 2010). Maternal education was frequently used as a proxy for SES, and was controlled or matched for in 
several studies (e.g. Czaja et al., 2011). Two cross-sectional and one longitudinal study found no association between maternal education and C-BE/LOC (Chen et al., 2009; Lamerz et al., 2005; Pauli-Pott et al., 2013). One study found no association between parental unemployment and LOC eating (Hartmann et al., 2012). Two studies found no associations between family structure and C-BE (Chen et al., 2009; Olvera et al., 2013). Finally, three studies found no association between race/ethnicity and C-BE (Chen et al., 2009; Olvera et al., 2013; Shomaker et al., 2010).

\section{DISCUSSION}

\subsection{Main findings and risk factor typology}

Weight teasing and parental under-involvement are the only family factors that can be classified as correlates of C-BE (Kraemer et al., 1997; Table 3). Parent weight, education, SES, and race/ethnicity were classified as non-correlates. Evidence was unclear for parent disordered eating, family weight and thinness concern, and maternal restraint/dieting. We found an insufficient number of studies $(\leq 2)$ to classify harsh discipline, mealtimes and feeding practices, attachment security, and family structure. Further, several putative correlates were assessed only once, and thus could not be included in synthesis (e.g., parent depression, material rewarding, parent-child conflict, parent arguing, etc.).

\subsection{Individual parent characteristics}

\subsubsection{Parent weight}

Parent weight was not associated with $\mathrm{C}-\mathrm{BE}$, and was classified as a non-correlate. However, measures varied across studies. Parent weight status was assessed via measured (Stice et al., 1999) or self-reported (Decaluwé et al., 2006) height and weight, or parent-reported “obesity risk” (Hartmann et al., 2012). 
Obesity is strongly associated with adult BE (de Zwaan, 2001), and both childhood adiposity (Wardle, Carnell, Haworth, \& Plomin, 2008) and adult BE are highly heritable (ReichbornKjennerud, Bulik, Tambs, \& Harris, 2004). These factors, combined with the association between dieting and adolescent BE (Goldschmidt et al., 2012), suggest that it is important to examine whether objectively measured parent weight is related to C-BE, and through what mechanisms.

\subsubsection{Parent eating disorder}

Findings about associations between parent disordered eating and C-BE were mixed, due to the varied types of disordered eating behaviors examined, so no conclusions can be drawn at this time. However, further research is warranted because children are likely to adopt eating patterns that are similar to other family members (Patrick \& Nicklas, 2005), and because heritability accounts for about $41 \%$ of variance in BE (Reichborn-Kjennerud et al., 2004)

\subsubsection{Maternal restraint/dieting}

The relationship between maternal restraint/dieting and C-BE is unclear. Research on parent dieting and child eating behavior has focused on preschool-age children (e.g., Birch \& Fisher, 2000), which may explain why Stice et al., (1999) found positive effects, whereas others did not (Haines et al., 2010; Hartmann et al., 2012).

\subsubsection{Parent education, SES, family structure, and race/ethnicity}

Parent education/SES, and race/ethnicity were classified as non-correlates according to the typology. However, further research is needed, given the homogeneity of samples in this review. Growing awareness that eating disorders impact people from all race/ethnic and SES backgrounds, and that BE rates are high among minorities (Swanson et al., 2011) highlight the need for detailed reporting on demographic characteristics of eligible and included participants. 


\subsection{Relational family characteristics}

\subsubsection{Weight teasing}

Overall, findings suggest that weight teasing is cross-sectionally associated with C-BE. However, temporal order has not been established. Weight teasing predicts adolescent BE (Haines, Neumark-Sztainer, Eisenberg, \& Hannan, 2006), and children who experience weight teasing from parents are more likely to experience it from siblings (Keery, Boutelle, van den Berg, \& Thompson, 2005). Weight teasing also places children at risk for depression and suicidal ideation (Eisenberg, Neumark-Sztainer, \& Story, 2003). In order to ascertain whether teasing from specific sources has differential effects on $\mathrm{C}-\mathrm{BE}$, it is important that validated measures to identify sources of teasing are used.

\subsubsection{Family weight and thinness concern}

Inconsistent results and methods across studies in sample recruitment/age, measures, and design prevent us from drawing conclusions about the association between family weight concern and C-BE. Parent weight concern is related to use of restrictive feeding practices (Gray, Janicke, Wistedt, \& Dumont-Driscoll, 2010), which can counterproductively induce children's disinhibited eating (Birch, Fisher, \& Davison, 2003). Parent weight concern is also related to children's body dissatisfaction (Anschutz, Kanters, Van Strien, Vermulst, \& Engels, 2009) and low self-esteem (Davison \& Birch, 2001), all of which are correlated with C-BE (Marcus \& Kalarchian, 2003).

\subsubsection{Parenting behavior}

Across three studies, findings suggest that maternal ignoring (e.g., emotional unresponsiveness), but not harsh discipline, is a correlate of C-BE. Mechanisms are unknown, but these findings corroborate others that suggest that parental involvement and emotion 
responsiveness to the child may be important for the development of emotion and appetite selfregulation (Harshaw, 2008; Birch \& Anzman, 2010; Saltzman, Liechty, Bost, Fiese, \& STRONG KIDS Team, 2016).

\subsubsection{Mealtimes and feeding practices}

Too few studies assessed mealtimes or parent feeding practices and C-BE to make summative statements. Mealtime studies assessed evening-meals only, although "family mealtimes" can occur throughout the day. Which meal, and which family members are present may differ in importance across cultures (Fiese et al., 2002), which no studies assessed. Most studies assessing feeding practices use samples of preschoolers (Faith, Scanlon, Birch, Francis, $\&$ Sherry, 2004). Since school age children and pre-teens have far more autonomy in food choices than preschoolers, observable effects of feeding practices on older children's eating may be limited (Matton et al., 2013). However, maternal use of restrictive feeding predicts children's eating in the absence of hunger (Birch et al., 2003; Fisher \& Birch, 2002), highlighting the need to examine correlates that may be specific to $\mathrm{C}-\mathrm{BE}, \mathrm{LOC}$, and eating in the absence of hunger.

\subsubsection{Attachment security}

There are too few studies to draw conclusions on the association between attachment security and C-BE. However, findings from the two studies available suggest that low attachment security may be a correlate for C-BE (Goossens et al., 2011). Longitudinally, low attachment security predicted persistence —not onset—of C-BE (Goossens et al., 2012). Among adults, low attachment security predicts disordered eating indirectly through use of maladaptive emotion regulation strategies (Tasca \& Balfour, 2014), and among children, attachment partially mediates associations between low self-esteem and C-BE (Goossens et al., 2011). Internal working models of attachment are the basis for how children learn to regulate emotion (Amini et al., 1996), and 
may inform how children's attachment security affects their self-regulatory capabilities

(Cummings \& Miller-Graff, 2015). The quality of the attachment relationship - the degree to which the child feels emotionally secure in the family — predicts general internalizing and externalizing problems, but has not yet been explored in relation to C-BE (Davies \& Woitach, 2008).

\subsection{Research recommendations}

This review uncovered over 40 constructs that have been examined as correlates or putative risk factors for $\mathrm{C}-\mathrm{BE}$, but only 11 of these have been examined in three or more studies, often by the same research group using the same sample. This review identified constructs that warrant further research and methods that would strengthen the field, such as prospective designs and observational measures. Few prospective studies examined the effects of weight teasing, parent disordered eating, attachment security, feeding practices, mealtimes, or maternal restraint/dieting on C-BE. Moreover, the majority of studies in this review relied on self-reported data; moving forward, it will be important to develop and utilize innovative observational or interview measures of family correlates of C-BE. Cultural characteristics - such as acculturation (Rhea \& Thatcher, 2013), and mealtime routines (Fiese et al., 2002) —affect aspects of the food environment relevant for C-BE. The unclear results on associations between $\mathrm{C}-\mathrm{BE}$ and feeding and eating in the home (e.g. maternal dieting, family mealtimes, feeding practices, and parent's disordered eating) suggest complexity in these associations, and highlight the need for closer examination of developmental and cultural influences. Finally, we found that research on C-BE among racially/ethnically diverse families is lacking; inclusion of minority families may yield important insights for tailoring prevention/intervention programs. 


\subsection{Strengths and limitations}

This study was limited to peer-reviewed, English-language articles, and may have missed international research on $\mathrm{C}-\mathrm{BE}$ and gray literature. Although risk of publication bias is a common phenomenon, the majority of all associations reported were non-significant, suggesting that both significant and non-significant findings were reported. Finally, studies examining other potentially relevant eating behaviors — such as food addiction or overeating — were not included. Despite limitations, this review of family correlates of BE in children is novel and timely, adheres to established guidelines for systematic reviews, and makes an important contribution to this expanding area of research.

\section{CONCLUSIONS}

Across studies, weight-related teasing and parental emotional non-responsiveness were the only family factors classified as correlates of child binge eating (C-BE). In contrast, parent's weight, education/SES, and race/ethnicity were not associated with C-BE. These findings suggest that C-BE is associated with parent's weight-related beliefs — but not their weight—and the emotional availability — but not the income - that they convey to their children. Thus, increasing parents' sensitivity towards weight-related comments, and strengthening parents' attunement to their children's emotional needs, may reduce risk of C-BE. Continued consideration of the family is imperative for a full understanding of the context in which C-BE develops. Further research is needed that tests whether alterations in family correlates or risk factors can reduce or prevent child binge eating. 


\section{Acknowledgements}

JAS was supported by the Agriculture and Food Research Initiative of the USDA National Institute of Food and Agriculture under the Illinois Transdisciplinary Obesity Prevention Program grant (2011-67001-30101) to the Division of Nutritional Sciences at the University of Illinois. No funders had any role in study design, data collection, analysis or interpretation of data, writing the manuscript, or the decision to submit the paper for publication. The authors would like to acknowledge Elizabeth A. Badskey, BSW for her contributions to the research project.

\section{References}

American Psychiatric Association \& DSM-5 Task Force. (2013). Diagnostic and statistical manual of mental disorders: DSM-5. Retrieved from http://dsm.psychiatryonline.org/book.aspx?bookid=556

Amini, F., Lewis, T., Lannon, R., Louie, A., Baumbacher, G., McGuinness, T., \& Schiff, E. Z. (1996). Affect, attachment, memory: Contributions toward psychobiologic integration. Psychiatry, 59(3), 213-239.

Anschutz, D. J., Kanters, L. J. A., Van Strien, T., Vermulst, A. A., \& Engels, R. C. M. E. (2009). Maternal behaviors and restrained eating and body dissatisfaction in young children. International Journal of Eating Disorders, 42(1), 54-61. http://doi.org/10.1002/eat.20569

Araujo, D. M. R., Santos, G. F. da S., \& Nardi, A. E. (2010). Binge eating disorder and depression: A systematic review. The World Journal of Biological Psychiatry, 11(2-2), 199-207. http://doi.org/10.3109/15622970802563171

Birch, L. L., \& Anzman, S. L. (2010). Learning to eat in an obesogenic environment: a 
developmental systems perspective on childhood obesity. Child Development Perspectives, 4(2), 138-143. doi: 10.1111/j.1750-8606.2010.00132.x

Birch, L. L., \& Fisher, J. O. (2000). Mothers' child-feeding practices influence daughters' eating and weight. American Journal of Clinical Nutrition, 71(5), 1054-1061. Retrieved from http://ajcn.nutrition.org/

Birch, L. L., Fisher, J. O., \& Davison, K. K. (2003). Learning to overeat: maternal use of restrictive feeding practices promotes girls' eating in the absence of hunger. American Journal of Clinical Nutrition, 78(2), 215-220. Retrieved from http://ajcn.nutrition.org/

Bronfenbrenner, U. (1979). Contexts of child rearing: Problems and prospects. American Psychologist, 34(10), 844-850. http://doi.org/10.1037/0003-066X.34.10.844

Chen, E. Y., McCloskey, M. S., \& Kathryn, K. E. (2009). Subtyping dietary restraint and negative affect in a longitudinal community sample of girls. International Journal of Eating Disorders, 42(3), 275-283. doi: 10.1002/eat.20661

Cummings, E. M., \& Miller-Graff, L. E. (2015). Emotional security theory: An emerging theoretical model for youths' psychological and physiological responses across multiple developmental contexts. Current Directions in Psychological Science, 24(3), 208-213. doi: $10.1177 / 0963721414561510$

Czaja, J., Hartmann, A. S., Rief, W., \& Hilbert, A. (2011). Mealtime family interactions in home environments of children with loss of control eating. Appetite, 56(3), 587-593. doi: 10.1016/j.appet.2011.01.030

Czaja, J., Rief, W., \& Hilbert, A. (2009). Emotion regulation and binge eating in children. International Journal of Eating Disorders, 42(4), 356-362. doi: 10.1002/eat.20630 
Davies, P. T., \& Woitach, M. J. (2008). Children's emotional security in the interparental relationship. Current Directions in Psychological Science, 17(4), 269-274. doi: 10.1111/j.1467-8721.2008.00588.x

Davison, K. K., \& Birch, L. L. (2001). Weight status, parent reaction, and self-concept in fiveyear-old girls. Pediatrics, 107(1), 46-53. doi: 10.1542/peds.107.1.46

Decaluwé, V., Braet, C., Moens, E., \& Van Vlierberghe, L. (2006). The association of parental characteristics and psychological problems in obese youngsters. International Journal of Obesity, 30(12), 1766-1774. doi: 10.1038/sj.ijo.0803336

de Zwaan, M. (2001). Binge eating disorder and obesity. International Journal of Obesity and Related Metabolic Disorders: Journal of the International Association for the Study of Obesity, 25 Suppl 1, S51-55. doi: 10.1038/sj.ijo.0801699

Eisenberg, M. E., Neumark-Sztainer, D., \& Story, M. (2003). Associations of weight-based teasing and emotional well-being among adolescents. Archives of Pediatrics \& Adolescent Medicine, 157(8), 733-738. doi: 10.1001/archpedi.157.8.733

Faith, M. S., Scanlon, K. S., Birch, L. L., Francis, L. A., \& Sherry, B. (2004). Parent-child feeding strategies and their relationships to child eating and weight status. Obesity Research, 12(11), 1711-1722. doi: 10.1038/oby.2004.212

Field A. E., Javaras K. M., Aneja P., Kitos, N., Camargo, C. A., Barr Taylor, C., Laird, N. M. (2008). Family, peer, and media predictors of becoming eating disordered. Archives of Pediatrics \& Adolescent Medicine, 162(6), 574-579. doi: 10.1001/archpedi.162.6.574

Fiese, B. H., Tomcho, T. J., Douglas, M., Josephs, K., Poltrock, S., \& Baker, T. (2002). A review of 50 years of research on naturally occurring family routines and rituals: Cause for 
celebration? Journal of Family Psychology, 16(4), 381-390. doi: 10.1037/08933200.16 .4 .381

Fisher, J. O., \& Birch, L. L. (2002). Eating in the absence of hunger and overweight in girls from 5 to 7 y of age. The American Journal of Clinical Nutrition, 76(1), 226-231. Retrieved from http://ajcn.nutrition.org/

Goldschmidt, A. B., Engel, S. G., Wonderlich, S. A., Crosby, R. D., Peterson, C. B., Le Grange, D., ... Mitchell, J. E. (2012). Momentary affect surrounding loss of control and overeating in obese adults with and without Binge Eating Disorder. Obesity, 20(6), 12061211. doi: 10.1038/oby.2011.286

Goldschmidt, A. B., Tanofsky-Kraff, M., Goossens, L., Eddy, K. T., Ringham, R., Yanovski, S. Z., ... Yanovski, J. A. (2008). Subtyping children and adolescents with loss of control eating by negative affect and dietary restraint. Behaviour Research and Therapy, 46(7), 777-787. doi: 10.1016/j.brat.2008.03.004

Goossens, L., Braet, C., Bosmans, G., \& Decaluwé, V. (2011). Loss of control over eating in preadolescent youth: The role of attachment and self-esteem. Eating Behaviors, 12(4), 289295. doi: 10.1016/j.eatbeh.2011.07.005

Goossens, L., Braet, C., Durme, K. V., Decaluwé, V., \& Bosmans, G. (2012). The Parent-Child Relationship as Predictor of Eating Pathology and Weight Gain in Preadolescents. Journal of Clinical Child \& Adolescent Psychology, 41(4), 445-457. doi: $10.1080 / 15374416.2012 .660690$

Gray, W. N., Janicke, D. M., Wistedt, K. M., \& Dumont-Driscoll, M. C. (2010). Factors associated with parental use of restrictive feeding practices to control their children's food intake. Appetite, 55(2), 332-337. doi: 10.1016/j.appet.2010.07.005 
Grusec, J. E., \& Davidov, M. (2015). Analyzing socialization from a domain-specific perspective. In J. E. Grusec \& P. D. Hastings (Eds.), Handbook of socialization: Theory and research (2nd ed.) (pp. 158-181). New York, NY, US: Guilford Press.

Haines, J., Gillman, M. W., Rifas-Shiman, S., Field, A. E., \& Austin, S. B. (2010). Family dinner and disordered eating behaviors in a large cohort of adolescents. Eating Disorders, 18(1), 10-24. doi: 10.1080/10640260903439516

Haines, J., Neumark-Sztainer, D., Eisenberg, M. E., \& Hannan, P. J. (2006). Weight teasing and disordered eating behaviors in adolescents: Longitudinal findings from Project EAT (Eating Among Teens). Pediatrics, 117(2), e209-e215. doi: 10.1542/peds.2005-1242

Hartmann, A. S., Czaja, J., Rief, W., \& Hilbert, A. (2012). Psychosocial risk factors of loss of control eating in primary school children: A retrospective case-control study. International Journal of Eating Disorders, 45(6), 751-758. doi: 10.1002/eat.22018

Keery, H., Boutelle, K., van den Berg, P., \& Thompson, J. K. (2005). The impact of appearancerelated teasing by family members. Journal of Adolescent Health, 37(2), 120-127. doi:10.1016/j.jadohealth.2004.08.015

Kraemer H., Kazdin A. E., Offord D. R., Kessler R. C., Jensen P. S., \& Kupfer D. J. (1997). Coming to terms with the terms of risk. Archives of General Psychiatry, 54(4), 337-343. doi:10.1001/archpsyc.1997.01830160065009

Lamerz, A., Kuepper-Nybelen, J., Bruning, N., Wehle, C., Trost-Brinkhues, G., Brenner, H., ... Herpertz-Dahlmann, B. (2005). Prevalence of obesity, binge eating, and night eating in a cross-sectional field survey of 6-year-old children and their parents in a German urban population. Journal of Child Psychology and Psychiatry, and Allied Disciplines, 46(4), 385-393. doi: 10.1111/j.1469-7610.2004.00363.x 
Marcus, M. D., \& Kalarchian, M. A. (2003). Binge eating in children and adolescents. International Journal of Eating Disorders, 34 Suppl, S47-57. doi: 10.1002/eat.10205

Matherne, C. E., Tanofsky-Kraff, M., Altschul, A. M., Shank, L. M., Schvey, N. A., Brady, S. M., ... Yanovski, J. A. (2015). A preliminary examination of Loss of Control Eating Disorder (LOC-ED) in middle childhood. Eating Behaviors, 18, 57-61. doi: 10.1016/j.eatbeh.2015.04.001

Matton, A., Goossens, L., Braet, C., \& Van Durme, K. (2013). Continuity in primary school children's eating problems and the influence of parental feeding strategies. Journal of Youth and Adolescence, 42(1), 52-66. doi: 10.1007/s10964-012-9794-3

Moher, D., Liberati, A., Tetzlaff, J., \& Altman, D. G. (2009). Preferred reporting items for systematic reviews and meta-analyses: the PRISMA statement. BMJ, 339, b2535. doi: 10.1136/bmj.b2535

NHLBI. (2014, February). Background: Development and use of study quality assessment tools. US Department of Health and Human Services. Retrieved from http://www.nhlbi.nih.gov/health-pro/guidelines/in-develop/cardiovascular-riskreduction/tools/background

Olvera, N., Dempsey, A., Gonzalez, E., \& Abrahamson, C. (2013). Weight-related teasing, emotional eating, and weight control behaviors in Hispanic and African American girls. Eating Behaviors, 14(4), 513-517. doi: /10.1016/j.eatbeh.2013.06.012

Patrick, H., \& Nicklas, T. A. (2005). A Review of Family and Social Determinants of Children's Eating Patterns and Diet Quality. Journal of the American College of Nutrition, 24(2), 83-92. doi: 10.1080/07315724.2005.10719448 
Pauli-Pott, U., Becker, K., Albayrak, Ö., Hebebrand, J., \& Pott, W. (2013). Links between psychopathological symptoms and disordered eating behaviors in overweight/obese youths. International Journal of Eating Disorders, 46(2), 156-163. doi:

10.1002/eat.22055

Pearson, C. M., Zapolski, T. C. B., \& Smith, G. T. (2015). A longitudinal test of impulsivity and depression pathways to early binge eating onset: Two pathways for early binge eating onset. International Journal of Eating Disorders, 48(2), 230-237. doi: 10.1002/eat.22277

Reichborn-Kjennerud, T., Bulik, C. M., Tambs, K., \& Harris, J. R. (2004). Genetic and environmental influences on binge eating in the absence of compensatory behaviors: A population-based twin study. International Journal of Eating Disorders, 36(3), 307-314. doi: 10.1002/eat.20047

Rhea, D. J., \& Thatcher, W. G. (2013). Ethnicity, ethnic identity, self-esteem, and at-risk eating disordered behavior differences of urban adolescent females. Eating Disorders, 21(3), 223-237. doi: 10.1080/10640266.2013.779177

Saltzman, J. A., Liechty, J. M., Bost, K. K., Fiese, B. H., \& the STRONG KIDS Team. (in press). Parent binge eating and restrictive feeding practices: Indirect effects of parent reactions to child negative emotion. Eating Behaviors. doi: 10.1016/j.eatbeh.2016.02.001

Sanderson, S., Tatt, I. D., \& Higgins, J. P. T. (2007). Tools for assessing quality and susceptibility to bias in observational studies in epidemiology: a systematic review and annotated bibliography. International Journal of Epidemiology, 36(3), 666-676. doi: 10.1093/ije/dym018

Shomaker, L. B., Tanofsky-Kraff, M., Elliott, C., Wolkoff, L. E., Columbo, K. M., Ranzenhofer, L. M., ... Yanovski, J. A. (2010). Salience of loss of control for pediatric binge episodes: 
does size really matter? International Journal of Eating Disorders, 43(8), 707-716. doi: 10.1002/eat.20767

Spanos, A., Klump, K. L., Alexandra, S., McGue, M., \& Iacono, W. G. (2010). A longitudinal investigation of the relationship between disordered eating attitudes and behaviors and parent-child conflict: A monozygotic twin differences design. Journal of Abnormal Psychology, 119(2), 293-299. doi: 10.1037/a0019028

Stang, A. (2010). Critical evaluation of the Newcastle-Ottawa scale for the assessment of the quality of nonrandomized studies in meta-analyses. European Journal of Epidemiology, 25(9), 603-605. doi: 10.1007/s10654-010-9491-z

Stice, E., Agras, W. S., \& Hammer, L. D. (1999). Risk factors for the emergence of childhood eating disturbances: A five-year prospective study. International Journal of Eating Disorders, 25(4), 375-387. doi: 10.1002/(SICI)1098-108X(199905)25:4<375::AIDEAT2>3.0.CO;2-K

Swanson, S. A., Crow, S. J., Le Grange, D., Swendsen, J., \& Merikangas, K. R. (2011). Prevalence and correlates of eating disorders in adolescents: Results from the national comorbidity survey replication adolescent supplement. Archives of General Psychiatry, 68(7), 714-723. doi: 10.1001/archgenpsychiatry.2011.22

Tanofsky-Kraff, M., Faden, D., Yanovski, S. Z., Wilfley, D. E., \& Yanovski, J. A. (2005). The perceived onset of dieting and loss of control eating behaviors in overweight children. International Journal of Eating Disorders, 38(2), 112-122. doi: 10.1002/eat.20158

Tanofsky-Kraff, M., Marcus, M. D., Yanovski, S. Z., \& Yanovski, J. A. (2008). Loss of Control Eating Disorder in children age 12y and younger: Proposed research criteria. Eating Behaviors, 9(3), 360-365. doi: 10.1016/j.eatbeh.2008.03.002 
Tasca, G. A., \& Balfour, L. (2014). Attachment and eating disorders: A review of current research. International Journal of Eating Disorders, 47(7), 710-717. doi: 10.1002/eat.22302

Wardle, J., Carnell, S., Haworth, C. M., \& Plomin, R. (2008). Evidence for a strong genetic influence on childhood adiposity despite the force of the obesogenic environment. American Journal of Clinical Nutrition, 87(2), 398-404. Retrieved from http://ajcn.nutrition.org/

White, M. A., \& Grilo, C. M. (2011). Diagnostic efficiency of DSM-IV indicators for binge eating episodes. Journal of Consulting and Clinical Psychology, 79(1), 75-83. doi: $10.1037 / \mathrm{a} 0022210$ 
Table 1

Inclusion and exclusion criteria

\begin{tabular}{|c|c|}
\hline Inclusion criteria & Exclusion criteria \\
\hline 1. Publication between 1980 and April 2015 & 1. Sample size $n \leq 10$ \\
\hline 2. Peer-reviewed & 2. Qualitative data only \\
\hline 3. English or English-translation available & 3. Measures validation study only \\
\hline \multirow{2}{*}{ 4. Sample size $n>10$} & 4. Lack of validated or standardized \\
\hline & assessment of LOC, BED, or BE \\
\hline 5. Mean sample age $\leq 12$-years, or presents & 5. C-BE outcomes measured only in the \\
\hline disaggregated data for children age $\leq 12$ & presence of compensatory behavior, as in \\
\hline years & Bulimia \\
\hline \multicolumn{2}{|l|}{ 6. Used validated or standardized } \\
\hline assessment of LOC eating, BED or BE & 6. No data about family correlates presented \\
\hline behaviors in the absence of compensatory & \\
\hline
\end{tabular}

7. Quantitative data presented

8. In longitudinal studies, C-BE was

modeled as a dependent variable, and family

factors were modeled as independent

variables

9. Presented data on the association between

$\mathrm{BE}$ and family correlates 
Figure 1

Flow chart showing search and selection process based on the Preferred Reporting Items for Systematic Reviews and Meta-Analyses (PRISMA) guidelines (www.prisma-statement.org)

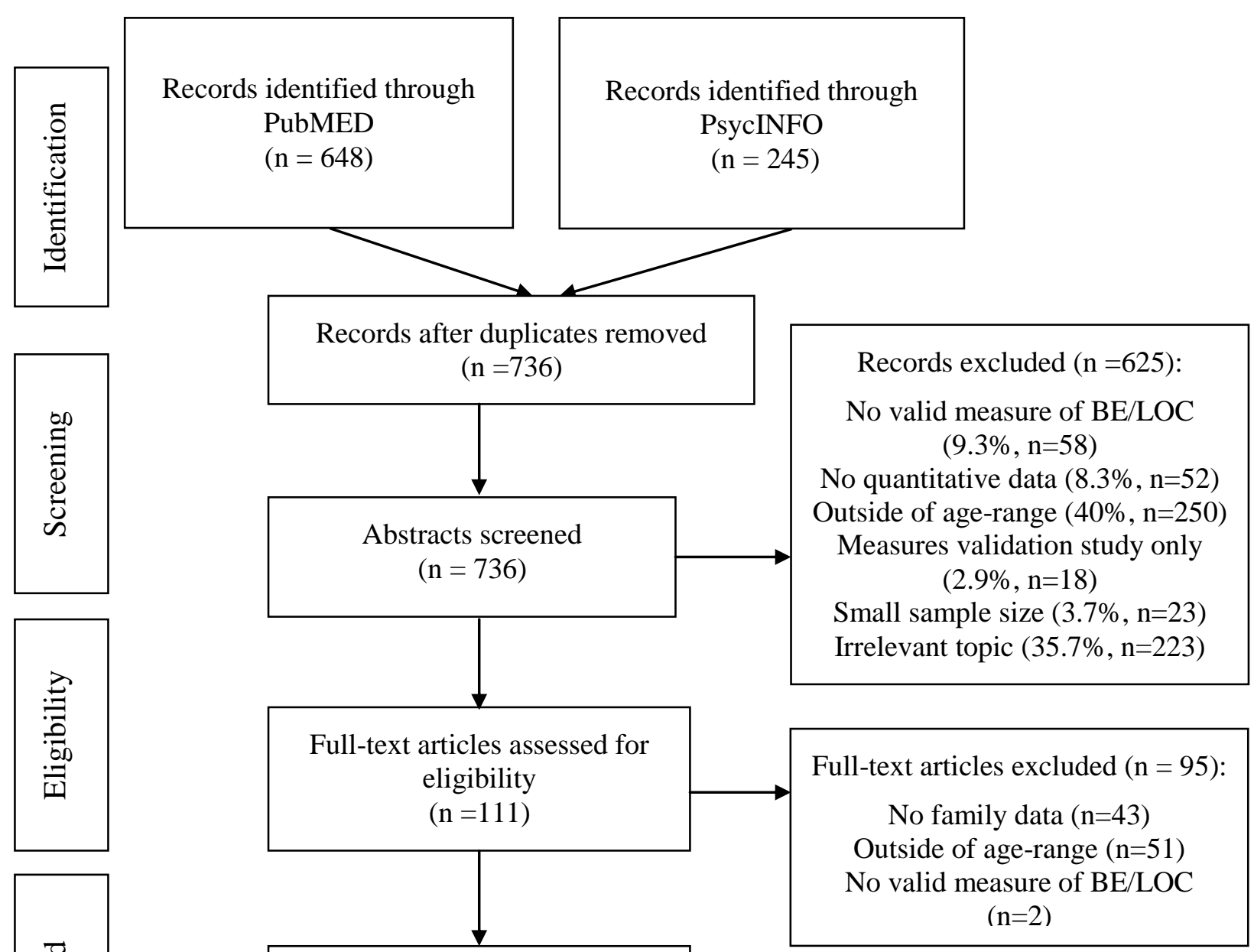

Studies included in tables and narrative synthesis $(\mathrm{n}=15)$ 
FAMILY CORRELATES OF CHILD BINGE EATING

Table 2

Characteristics and results of reviewed studies for family correlates of binge eating ( $n=15$ studies)

\begin{tabular}{|c|c|c|c|c|}
\hline $\begin{array}{c}\text { Author(Year) } \\
\text { Country }\end{array}$ & Recruitment & Sample Characteristics & $\begin{array}{c}\text { Study } \\
\text { Design }\end{array}$ & Measures \& Results \\
\hline $\begin{array}{l}\text { Chen et al., } \\
\text { (2009). } \\
\text { (US) }\end{array}$ & $\begin{array}{l}\text { Stratified random } \\
\text { household sampling } \\
\text { with over-sampling } \\
\text { for low-income } \\
\text { participants } \\
\text { (Control: Girls from } \\
\text { the same sample } \\
\text { deemed not at risk for } \\
\text { binge eating). }\end{array}$ & $\begin{array}{l}\mathrm{n}=543 \\
\text { Female }(100 \%) \\
\text { African American }(54.1 \%) \text {, Multiracial }(4.8 \%) \text {, Asian } \\
(0.4 \%) \text {, Caucasian }(40.5 \%) \\
\text { Obese }(23 \%) \\
\text { On public assistance }(29.5 \%) \\
\text { Less than high school education }(19.5 \%) \\
\text { Mean age }=10.7 \text { years old (Follow-up at } 12 \text { and } 14 \\
\text { [results from age } 10 \text { and } 12 \text { only included in this review], } \\
\text { Range }[\mathrm{NR}])\end{array}$ & $\begin{array}{l}\text { Longitudinal } \\
\text { cohort }^{\mathrm{a}}\end{array}$ & $\begin{array}{l}\text { ChEAT: Binge eating }{ }^{(\mathrm{DV})} \\
\text { Demographics: SES }^{(\mathrm{NS})} \text {, Parent education } \\
{ }^{(\mathrm{NS})} \text {; Race/ethnicity }{ }^{(\mathrm{NS})} \text {; Intact family }{ }^{(\mathrm{NS})}\end{array}$ \\
\hline $\begin{array}{l}\text { Czaja et al., } \\
(2011) \text {. } \\
(\mathrm{DE})\end{array}$ & $\begin{array}{l}\text { School- and } \\
\text { community-based } \\
\text { recruitment } \\
\text { (Control: Same } \\
\text { sample, children with } \\
\text { no LOC eating } \\
\text { matched on age, sex, } \\
\text { BMI\%tile, education } \\
\text { and maternal } \\
\text { education) }\end{array}$ & $\begin{array}{l}\mathrm{n}=74 \text { (Case: } \mathrm{n}=43 \text {, Control: } \mathrm{n}=31) \\
\text { Female }(60 \%) \\
\text { Race/ethnicity }(\mathrm{NR}) \\
\text { Overweight }(14.8 \%) \text {, Obese }(10.4 \%), \text { Extremely obese } \\
(4.4 \%) \\
\text { Low SES }(62.1 \%), \text { High SES }(37.8 \%) \\
\text { Mean age }=10.8 \text { years old (Range: } 8-13)\end{array}$ & $\begin{array}{l}\text { Cross- } \\
\text { sectional case- } \\
\text { control }\end{array}$ & 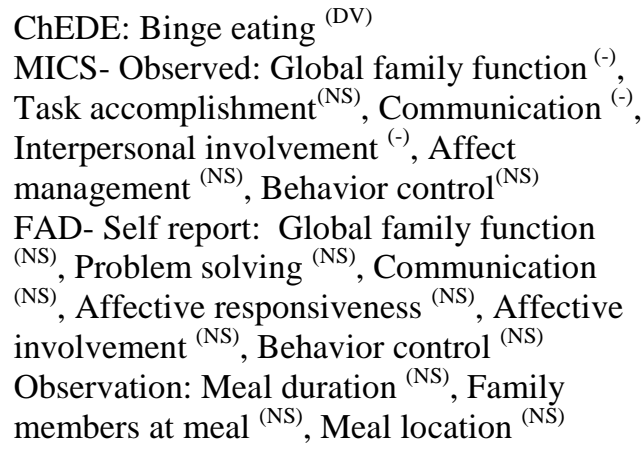 \\
\hline $\begin{array}{l}\text { Decaluwé et } \\
\text { al., (2006). } \\
\text { (BE) }\end{array}$ & $\begin{array}{l}\text { Treatment-seeking } \\
\text { sample of obese } \\
\text { children and their } \\
\text { parents }\end{array}$ & $\begin{array}{l}\text { Children: } \mathrm{n}=196 \text { (Mothers: } \mathrm{n}=162 \text {, Fathers: } \mathrm{n}=131 \text { ) } \\
\text { Female (children; } 60.2 \%) \\
\text { Race/ethnicity (NR) } \\
\text { Obese }(100 \%) \\
\text { SES (NR) } \\
\text { Mean age }=12.7 \text { years old (Range: } 10-16)\end{array}$ & $\begin{array}{l}\text { Cross- } \\
\text { sectional }\end{array}$ & 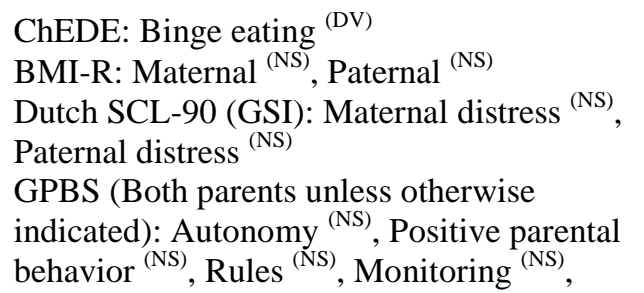 \\
\hline
\end{tabular}


Field et al. (2008).

$\begin{array}{ll}\text { Goossens et } & \text { School-based } \\ \text { al., (2011). } & \text { recruitment } \\ \text { (BE) } & \text { (Control: Same } \\ & \text { sample) }\end{array}$

Goossens et al., (2012). (BE)

Haines et al., (2010)

(US)
Growing Up Today Study (GUTS), children of nurses in the Nurses' Health Study II

sample

School-based recruitment $\mathrm{n}=11,087$

Female $(55.8 \%)$

White (>90\%)

Overweight or obese (Females, 19.8\%; Males, 23.2\%)

SES (NR)

Mean age $=12$ years old (Range: $9-14$ )

$\mathrm{n}=482$ (Case: $\mathrm{n}=85$, Control: $\mathrm{n}=397$ )

Female (47.2\%)

Race/ethnicity (NR)

Overweight/ obese (NR)

SES $^{\mathrm{d}}$ : Upper (0.6\%), Upper-middle (22.4\%), Middle (63.4\%), Lower-middle (12.6\%), and Lower (1\%)

Parents' marital/cohabitation status: Married and living together $(73.6 \%)$, Not married and living together $(6.2 \%)$, Divorced (19.2\%), Widowed (1\%)

Mean age $=9.02$ years old (Range: $8-11$ )

$\mathrm{n}=601$ (Case: SBE [n=156], OBE [n=110]; Control, NR) Female (48\%)

Race/ethnicity (NR)

Baseline: Overweight, Obese $(11 \%, 2 \%)$

One-year follow-up: Overweight, Obese $(12 \%, 4 \%)$

SES (NR)

Mean age (baseline) $=9.1$ years old (Range: $8-11$ )

$\mathrm{n}=13,448$

Female $(55.8 \%)$

White (>90\%)

Overweight, Obese (Females, 19.8\%; Males, 23.2\%)

SES (NR)

Mean age $=11.9$ years old (Range: $9-14$ )
Material rewarding ${ }^{(\mathrm{NS})}$, Discipline $\mathrm{e}^{(\mathrm{NS})}$, Harsh punishment ${ }^{(\mathrm{NS})}$, Ignoring (Maternal [+]; Paternal [NS]) Inconsistent discipline ${ }^{(\mathrm{NS})}$
Cross-

sectional

YRBSS: Binge eating (DV),

MRFS: Weight importance to fathers ${ }^{(+)}$, NR/GUTS: Weight teasing ${ }^{(+)}$, Maternal eating disorder-self report ${ }^{\text {(NS) }}$

Cross-

sectional case control

Longitudinal cohort

ChEDE-Q: Binge eating (DV) SS-D: Secure attachment ${ }^{(-)}$
ChEDE-Q: LOC ${ }^{(\mathrm{DV})}$
Longitudinal cohort
SS-D: Secure attachment ${ }^{(-)}$
Study (GUTS),

the Nurses' Health

Study II

\author{
YRBSS: Binge eating (DV) \\ MRFS: Parents value thinness (NS) \\ NR/GUTS: Family mealtime ${ }^{(-)}$, Weight \\ teasing (parents) ${ }^{(\mathrm{NS})}$, Maternal dieting ${ }^{(\mathrm{NS})}$
}




$\begin{array}{ll}\begin{array}{l}\text { Hartmann, } \\ \text { Czaja, Rief \& } \\ \text { Hilbert, }\end{array} & \begin{array}{l}\text { School- and } \\ \text { community-based } \\ \text { (2012) }\end{array} \\ \text { recruitment } \\ \text { (Control: Same } \\ \text { sample matched by } \\ \text { sex, age, BMI\%tile, } \\ \text { grade level, and } \\ \text { maternal education) } \\ \text { Lamerz et al., } \\ \text { Clinic-based } \\ \text { (2005). } & \begin{array}{l}\text { recruitment, } \\ \text { population }\end{array} \\ \text { rDE) } & \text { representative }\end{array}$

Matton et al., School-based

(2013). recruitment of parents

(BE) and children

Olvera et al., (2013). (US) $\mathrm{n}=120$ (Case: $\mathrm{n}=60$, Control: $\mathrm{n}=60)$

Female $(56.6 \%)$

Race/ethnicity (NR)

Overweight, Obese $(29.2 \%, 30.8 \%)$

SES proxy: Maternal education (matched)

Mean age $=10.77$ years old (Range: $8-13$ )

Children: $n=2020$, Parents: $n=1979$

Female (49.1\%)

Race/ethnicity (NR)

Overweight, Obese $(40.6 \%, 9 \%)$

SES Proxy: Maternal education (NR)

Mean age $=5.8$ years old (Range: $5-7$ )

$\mathrm{n}=613$ children, $\mathrm{n}=714$ parents (Mothers, $57.7 \%$ )

Female (46.5\%)

Race/ethnicity (NR)

Overweight, obese (Girls, 16.5\%, 2.8\%; Boys, 12.8\%, $2.5 \%$ )

SES ${ }^{\mathrm{d}}$ : Upper (37.2\%), Upper-middle (30.5\%), Middle $(31.6 \%)$, and Lower $(0.01 \%)$ class

Mean age $=9.05$ years old at Time $1,9.56$ years old at

Time 2 (Range: 8-11 at Time 1, and 8-12 at Time 2)

$\mathrm{n}=141$

Female (100\%)

Black (19\%), Hispanic/Latina (75\%)

Overweight, Obese $(19 \%, 81 \%)$

Acculturation: Low (11\%), Medium (53\%), High (36\%)

SES (NR)

Mean age $=11.1$ (Range: $9-14$ years $)$

$\mathrm{n}=128$

Pauli-Pott e

Clinic-referred sample

for weight loss

Female $(47.7 \%)$
Cross- ChEDE-German: Binge eating (IV/DV) sectional case ORFI $^{\text {b}}$ : Reported history of parent control overweight/obesity ${ }^{(\mathrm{NS})}$, Reported history of AN or BN ${ }^{(\mathrm{NS})}$, Critical comments from family about weight/shape ${ }^{(+)}$, Family weight concern $^{(\mathrm{NS})}$, Family member dieting ${ }^{(\mathrm{NS})}$, Parent depression ${ }^{(\mathrm{NS})}$, Parent arguments ${ }^{\text {(NS) }}$

Cross-

sectional

CQ: Binge eating (DV),

Demographics: Parent education ${ }^{(\mathrm{NS})}$

CIDI: Maternal binge eating ${ }^{(+)}$, Paternal binge eating ${ }^{(\mathrm{NS})}$

Longitudinal

cohort

ChEDE-Q: LOC ${ }^{\text {(DV) }}$

CFQ: Restriction ${ }^{(\mathrm{NS})}$, Pressuring ${ }^{(\mathrm{NS})}$, Monitoring (NS)

Cross-

sectional

MRFS: Binge eating ${ }^{(\mathrm{DV})}$, Weight teasingpeers ${ }^{(\mathrm{NS})}$, Weight teasing-parents ${ }^{(+)}$

Demographics: Race/ethnicity ${ }^{(\mathrm{NS})}$, Father present in home ${ }^{(\mathrm{NS})}$

Cross-

sectional
QEWP-P/A: Binge eating disorder ${ }^{\text {(DV) }}$ Demographics: Maternal education ${ }^{(\mathrm{NS})}$ 
(DE)

treatment-based recruitment

Shomaker et

al., (2010).

(US)

Non-intervention

clinical recruitment

(Control: Same

sample)

Spanos et al.,

(2010).

(US)

\section{Minnesota Twin \\ Study Pairs}

Hospital-based birth

cohort recruitment
Race/ethnicity (NR)

Overweight, Obese (100\%)

SES Proxy:

Maternal education: High-School/College (18.8\%)

Basic/Work education (70.4\%), No reply (10.9\%)

Paternal education: High-School/College (19.5\%),

Basic/Work education (58.6\%), No reply $(21.9 \%)$

Mean age $=11$ years old (Range: $7.5-15$ )

$\mathrm{n}=367$

Female (48\%)

White $(57.8 \%)$, Other $(42.2 \%)$

Overweight, Obese (NR)

SES : Hollingshead Index Median (Range)=2 (1-5)

Mean age $=12.7$ years old (Range: $6-17$ )

$\mathrm{n}=468$ monozygotic twins $(\mathrm{n}=234$ pairs $)$

Female $(100 \%)$

White $(>95 \%)$

Overweight, Obese (NR)

SES (NR)

Mean age at baseline $=11$ years old (all twins were 11 at baseline)

\section{$\mathrm{n}=216$}

Female $(46.3 \%)$

Race (Mother, Father): White $(88 \%, 86 \%)$, Black (1\%, $1 \%)$, Asian $(6 \%, 9 \%)$, Hispanic $(4 \%, 4 \%)$, Native

American (1\%, 0\%), Pacific Islander $(1 \%, 0 \%)$

Infant BMI (Mean=14.4)

SES proxy: Median parent education (College graduate)

Mean age at baseline $=3$ weeks old (Follow-up annually from 2-5 years old)
Cross- $\quad$ EDE$^{-} \mathrm{ChEDE}^{\mathrm{c}}$ : Binge eating (IV), sectional case Demographics: SES ${ }^{(\mathrm{NS})}$, Race/ethnicity ${ }^{(\mathrm{NS})}$ control

Longitudinal PEQ: Parent-child conflict ${ }^{\text {(NS) }}$

twin study ${ }^{d} \quad$ MEBS: Binge eating ${ }^{(D V)}$

\author{
Longitudinal Infant factors: \\ birth cohort CQ: Overeating (DV) \\ Maternal factors: \\ CQ: Weight ${ }^{(\mathrm{NS})}$, History of overweight ${ }^{(\mathrm{NS})}$ \\ TFEQ: Dieting/restraint ${ }^{(+)}$, Emotional \\ Eating ${ }^{(\mathrm{NS})}$, Hunger ${ }^{(\mathrm{NS})}$ \\ EDI: Drive for thinness ${ }^{(+)}$, Body \\ Dissatisfaction $^{(\mathrm{NS})}$, Bulimic symptoms ${ }^{(\mathrm{NS})}$
}

Note. DV = Dependent variable. Associations are shown as (+) positive, $(-)$ negative, or NS = non-significant. NA = Not applicable. NR $=$ not reported. SES =

Socioeconomic situation. ChEAT = Children's Eating Attitudes Test. MICS = Mealtime Interaction Coding Scheme. FAD = Family Assessment Device. ChEDE =

Eating Disorder Examination adapted for children. BMI-R = Body mass index- reported. BMIz-M = Body mass index z-score- measured. Dutch SCL-90 (GSI) =

Dutch symptom checklist-90. GBPS = Ghent Parental Behavior Scale. YRBSS = Youth Risk Behavior Surveillance System. MRFS = McKnight Risk Factor 
Survey = Dutch Symptom Checklist (General Symptomatic Index). GUTS = Growing Up Today Study. ChEDE-Q = Child Eating Disorder ExaminationQuestionnaire. SS-D = Security Scale- Dutch version. O-RFI = Oxford Risk Factor Interview. POTS = Perception of Teasing Scale. CQ = Constructed question. $\mathrm{CIDI}=$ Composite International Diagnostic Interview. CFQ = Child Feeding Questionnaire. QEWP-P/A = Parent/Adolescent version of Questionnaire of Eating and Weight Patterns. EDE = Eating Disorder Examination. PEQ = Parental Environment Questionnaire. MEBS = Minnesota Eating Behavior Survey. SR = Selfreport. TFEQ = Three Factor Eating Questionnaire. EDI = Eating Disorder Inventory.

${ }^{\mathrm{a}}$ Results reported are consistent in both 10- and 12-year-olds.

${ }^{b}$ Over 60 variables were reported from the Oxford Risk Factor Interview, however data were presented in the article for only 12 of the 60 . Of the 12 variables with data available, only 7 were related to families; therefore, these are the only correlates presented in this table from Hartmann et al., 2012.

${ }^{\mathrm{c}}$ Both ChEDE and EDE were used.

${ }^{\mathrm{d}}$ Longitudinal results from this study were outside the age range of interest (14 and 17 years at time 2 and time 3 , respectively), and so only baseline results (at 11 years old) are included in the synthesis of results. 
Table 3

Family correlates of binge eating in children

\begin{tabular}{|c|c|c|c|c|}
\hline Correlate & Positive association & Negative association & No association & $\begin{array}{c}\text { Risk factor } \\
\text { classification }^{\text {a }}\end{array}$ \\
\hline Parent weight & & & $\begin{array}{l}\text { Decaluwé et al., } 2006 \text { (CS) } \\
\text { Stice et al., } 1999 \text { (L) } \\
\text { Hartmann et al., } 2012 \text { (CS) }\end{array}$ & Non-correlate \\
\hline $\begin{array}{l}\text { Parent disordered } \\
\text { eating }\end{array}$ & $\begin{array}{l}\text { Lamerz et al., } 2005 \text { (CS; } \\
\text { binge eating) }\end{array}$ & & $\begin{array}{l}\text { Field et al., } 2008 \text { (CS; general ED) } \\
\text { Stice et al., } 1999 \text { (L; bulimic symptoms) } \\
\text { Hartmann et al., } 2012 \text { (CS; history of } \\
\text { AN/BN) }\end{array}$ & N/A \\
\hline Weight teasing & $\begin{array}{l}\text { Field et al., } 2008 \text { (CS; } \\
\text { father teasing) } \\
\text { Hartmann et al., } 2012 \\
\text { (CS; family teasing) } \\
\text { Olvera et al., 2013 (CS; } \\
\text { parent teasing) }\end{array}$ & & $\begin{array}{l}\text { Haines et al., } 2010 \text { (L; both parents } \\
\text { teasing) }\end{array}$ & Correlate \\
\hline $\begin{array}{l}\text { Family weight and } \\
\text { thinness concern }\end{array}$ & $\begin{array}{l}\text { Stice et al., } 1999 \text { (L) } \\
\text { Field et al., } 2008 \text { (CS) }\end{array}$ & & $\begin{array}{l}\text { Haines et al., } 2010 \text { (L) } \\
\text { Hartmann et al., } 2012 \text { (CS) }\end{array}$ & Unclear \\
\hline Parenting behavior & $\begin{array}{l}\text { Decaluwé et al., } 2006 \\
\text { (CS; ignoring) } \\
\text { Czaja et al., } 2011 \text { (CS; } \\
\text { under-involvement) } \\
\text { Hartmann et al., 2012 } \\
\text { (CS; under-involvement) }\end{array}$ & & $\begin{array}{l}\text { Decaluwé et al., } 2006 \text { (CS; harsh } \\
\text { discipline) } \\
\text { Czaja et al., } 2011 \text { (CS; harsh discipline) }\end{array}$ & $\begin{array}{l}\text { N/A (harsh discipline) } \\
\text { Correlate (ignoring, } \\
\text { under-involvement) }\end{array}$ \\
\hline
\end{tabular}


Maternal

restraint/dieting

Family mealtimes

and feeding

practices

Attachment

security

Parent education/

SES

Family structure

Race
Stice et al., 1999 (L)

Haines et al., 2010 (L)

Hartmann et al., 2012 (CS)

Haines et al., 2010 (L;

frequency)

Czaja et al., 2011 (CS;

communication)

Goossens et al., 2011 (CS)

Goossens et al., 2012 (L;

fathers only)
Czaja et al., 2011 (CS; mealtime duration, N/A meal location, family members at meal)

Matton et al., 2013 (L; feeding practices)

\section{N/A}

Shomaker et al., 2010 (CS; SES)

Chen et al., 2009 (L; SES/education)

Lamerz et al., 2005 (CS; education)

Pauli-Pott et al., 2013 (CS; education)

Hartmann et al., 2012 (CS;

unemployment)

Chen et al., 2009 (L; Intact family)

Olvera et al., 2013 (CS; Father present in

home)

Chen et al., 2009 (L)

Shomaker et al., 2010 (CS)

Olvera et al., 2013 (CS)

\section{A} /A

Unclear 